\section{LA EVALUACIÓN DE LA ESCRITURA CREATIVA EN EL CONTEXTO UNIVERSITARIO}

\author{
Pilar Vega Rodríguez \\ Universidad Complutense de Madrid \\ ORCID iD: https://orcid.org/0000-0002-5014-6855 \\ pvegarod@ucm.es
}

\section{CREATIVE WRITING ASSESSMENT IN THE ACADEMIC CONTEXT}

Cómo citar este artículo/Citation: Vega Rodríguez, Pilar (2020). La evaluación de la escritura creativa en el contexto universitario. Arbor, 196 (798): a579. https://doi.org/10.3989/ arbor.2020.798n4003

Recibido: 25 mayo 2020. Aceptado: 31 octubre 2020.

RESUMEN: Existe una larga tradición sobre las rúbricas pedagógicas de la escritura, principalmente referida a los niveles educativos no universitarios y con aplicación a la competencia lingüística en la lengua nativa o en una segunda lengua. En este trabajo se revisan los resultados de investigación referidos a la evaluación de la escritura creativa en niveles preuniversitarios y universitarios en contextos generales (no particularizados en zonas o culturas, sobre todo teniendo en cuenta la inexistencia de este tipo de bibliografía en lengua española), en cuanto corresponden al desarrollo de competencias en la lengua nativa, más allá de su empleo en el desarrollo del pensamiento crítico o en determinados ámbitos pedagógicos, y se ofrece una aproximación a los estándares de valoración del progreso de los estudiantes en esta disciplina.

PALABRAS CLAVE: Escritura creativa; evaluación; rúbricas; enseñanza universitaria.
Copyright: (C) 2020 CSIC. Este es un artículo de acceso abierto distribuido bajo los términos de la licencia de uso y distribución Creative Commons Reconocimiento 4.0 Internacional (CC BY 4.0).

ABSTRACT: There is a long tradition of pedagogical writing rubrics, mainly referring to non-university educational levels and with application to native or second language linguistic competence. This paper reviews research results referring to the evaluation of creative writing at pre-university and university levels in general contexts (not specified in areas or cultures, especially taking into account the inexistence of this type of bibliography in the Spanish language), and as they correspond to the development of competences in the native language, beyond their use in the development of critical thinking or in certain pedagogical fields. An approach is also offered for standards in assessing the progress of students in this discipline.

KEYWORDS: Creative writing; evaluation; rubrics; university education.. 


\section{LA EVALUACIÓN ARTÍSTICA Y LA ESCRITURA CREATIVA}

Como campo de estudio independiente, el estatuto de la escritura creativa ha ido fraguándose a lo largo del siglo XX para designar, principalmente, la composición de textos valiosos por una dimensión estética (dramáticos, poéticos, de ficción y no ficción) (Nezakatgoo, 2011: 748), y también otros tipos de escritura reflexiva y personal, o con aplicación al desarrollo de competencias (Rochford y Borchert, 2011; Vaezi y Rezaei, 2019).

En el contexto científico anglosajón son abundantes los estudios sobre métodos y parámetros de evaluación de la escritura, según corresponde a la larga tradición de la escritura creativa en todas las fases de la educación, en especial en la enseñanza primaria y secundaria. Pero en las últimas dos décadas la disciplina se ha incorporado oficialmente a los programas de grado y posgrado de las universidades, y las altas tasas de matriculación confirman no solo la particular necesidad expresiva de las nuevas generaciones sino el propósito de adquirir una de las competencias profesionales más demandadas en todos los entornos (Harper, 2016: 503). De un lado la creatividad: gracias a ella el estudiante podrá aplicar los conocimientos adquiridos a la resolución de todo tipo de problemas, profesionales, sociales y vitales. Y en segundo término, la competencia en el lenguaje oral y escrito, tan necesaria en todos los sectores profesionales e imprescindible en las empresas de información, entretenimiento y ocio (publicidad, periodismo, redacción, guionistas, videojuegos).

No parece fácil definir "lo creativo», asunto en el que andan comprometidos psicólogos, educadores y políticos (Kozbelt, Beghetto y Runco, 2010: 26-27). Se trata de un atributo que puede ser aplicado a personas, procesos y objetos (de uso común o artístico). Por "creativo» se entiende lo nuevo, original, de alto valor y calidad. Incluye las condiciones de relevancia, efectividad, elegancia, y naturalidad (Kaufman, Baer y Cole, 2009; Kaufman y Baer, 2012).

En el mundo del arte, tras un largo y complejo proceso de selección y aceptación de las obras en el que han participado las instituciones y los profesionales implicados (conservadores, galeristas, académicos, historiadores), han ido configurándose estándares de valoración más o menos objetiva de las obras. En este dominio la valoración de la creatividad suele hacerse a través de dos procedimientos: la prueba Torrance ${ }^{1}$ y la técnica de la evaluación consensuada (CAT). La primera trata de evaluar la singularidad de las respues- tas del sujeto creativo en función de su abundancia, flexibilidad, fluidez, divergencia, originalidad y elaboración (Gotesky y Breithaupt, 1978: 29). En la CAT se utiliza el juicio combinado, y no instruido previamente, de varios expertos en el campo, atendiendo exclusivamente a los objetos y productos, y sin tomar en cuenta prescripciones, ideas sobre la creatividad, o juicios de otros expertos ${ }^{2}$. La CAT ha sido recomendada como "el estándar de oro» de la creatividad (Baer y McKool, 2009: 2) ya que se apoya exclusivamente en la experiencia de los árbitros, no influidos por teorías previas de la creatividad (potencialmente superables) ni por valoraciones de otros expertos (ya que se trabaja de modo independiente). Tras concluir el procedimiento se constata generalmente un alto grado de consenso en las respuestas obtenidas. Por otra parte, esta técnica es lo suficientemente flexible como para adecuarse a todos los niveles de la creatividad, desde la genialidad hasta las realizaciones más escasas, a diferencia de lo realizado por la prueba Torrance, en exceso vinculada a estándares fijos ${ }^{3}$.

La única dificultad de esta técnica radica en decidir sobre el nivel de experiencia que necesitaría un "experto» para poder juzgar. De hecho, los resultados de investigación muestran la variación de juicios cuando los evaluadores no participan del mismo nivel de experiencia.

En el terreno de la escritura, la opinión de que su valoración solo puede hacerse "subjetivamente» es muy general. Desde esta perspectiva se considera que la «originalidad» no puede enseñarse y que un evaluador nunca podrá despojarse de sus gustos o prejuicios a la hora de pronunciarse sobre un texto (Kroll, 1997: 1). De ahí que muchos autores consideren imposible establecer parámetros objetivos para la valoración de la escritura (Blomer, 2011). Por otra parte, no resulta fácil aplicar en este campo las técnicas habituales de medición de la creatividad (Newman, 2007); por ejemplo en lo relativo al "pensamiento divergente» (Baer y McKool, 2009). Precisar en qué aspectos habría de valorarse la "originalidad» de la escritura no parece sencillo (si en el estilo, cadencia, personajes, descripciones, momentos, eventos dramáticos, escenas, tema, comprensión y tratamiento del tema, género, etc.). Por lo demás, si bien es cierto que la creatividad sobrepasa el ámbito de la corrección y destreza estilísticas tampoco la valoración de un texto puede dejar completamente al margen estos aspectos.

La investigación de Díaz Suárez (2015) se propuso indagar en los sectores profesionales relacionados con la escritura creativa para deducir si existían cri- 
terios, incluso tácitos o menos perfilados, análogos a los empleados en el mundo de arte y utilizados por los expertos y profesionales (profesores de creatividad y redacción, críticos competentes y editores de cuentos). Los resultados de Díaz Suárez rubricaron la inexistencia de estos criterios, en el marco de la short story, más allá de la importancia concedida a la «voz narrativa» (auténtica y personal), «la estructura» (consistente) o el "lenguaje estético». Lo prioritario para los expertos consultados fue la «recepción» y expectativas suscitadas por el texto -dependiendo del género literario, público o línea de la editorial- y no tanto los parámetros del valor formal o creativo. Más aún, la mayoría de los expertos opinaban que de existir esas rúbricas solo conseguirían recortar la originalidad de los autores. Lo único que debería valorarse, en todo caso, sería el esfuerzo de los escritores por revisar y corregir sus textos, pero no tanto la creatividad, esencialmente vinculada al juicio subjetivo (Newman, 2007).

Pero el hecho de que tanto escritores como editores o profesores sepan detectar cuándo un texto es bueno o malo, o en qué puntos podría mejorarse, evidencia un cierto valor objetivo en la escritura, al menos en el nivel de la competencia (Díaz Suárez, 2015: 28). $Y$ esto prueba que si la creatividad no puede ser enseñada, al menos sí es posible impulsarla, más allá de lo innato, fomentando el desarrollo de la sensibilidad literaria en entornos colaborativos (Blamires y Peterson, 2014). De ahí la propuesta de diseñar rúbricas fiables de medición (Rezaei y Lovorn, 2010; Blomer, 2011; Brookhart, 2013: 4-7; Mozaffari, 2013).

Lo que no puede negarse, con todo, es que solo en el contexto académico se «evalúa» la escritura. Es en los programas de enseñanza reglada y oficial donde los estudiantes tienen que demostrar la adquisición de las competencias asignadas al título por las instancias oficiales encargadas de su calidad. Fuera del aula, los textos se someten a la recepción de la crítica y del público lector -con repercusiones de índole cultural, social, económica-, pero la escritura no es calificada sino preferida o seleccionada.

\section{2. ÁRBITROS DE LA EVALUACIÓN, CRITERIOS Y PRO- CEDIMIENTOS}

La evaluación es un proceso inherente a la instrucción gracias al cual es posible comprobar el rendimiento de los estudiantes, la adecuación del curriculum diseñado, la eficacia de la metodología docente, y diagnosticar las fortalezas y debilidades en todos estos aspectos (Luft, 1997: 25). La evaluación tiene como objetivo el refuerzo del aprendizaje del estudiante; por eso requiere, como punto de partida, una clara definición de los objetivos del aprendizaje: conocimientos, comportamientos, acciones o artefactos de los estudiantes, esperables al final del proceso (Rochford y Borchert, 2011).

En un programa de escritura creativa los objetivos del aprendizaje deben aspirar tanto a la competencia en la escritura (claridad, flexibilidad, organización, corrección) como a la promoción de la originalidad, diversidad, singularidad y autenticidad de los textos de los estudiantes. En los estudios universitarios de «escritura creativa» estos objetivos y habilidades se traducen en piezas textuales que son valoradas dentro de un marco teórico específico (la teoría literaria y las herramientas y técnicas de creación, según Rodríguez, 2008) y que alcanzan su culminación en la tesis de posgrado o trabajo de fin de máster.

En líneas generales, los procedimientos de evaluación son dos, la evaluación holística y la analítica. La primera examina la calidad general del escrito y la segunda se centra en aspectos particulares de la escritura a través del examen de rúbricas concretas (Weigle, 2002; Silvia, Martin y Nusbaum, 2009; Vaezi y Rezaei, 2019). La prioridad de una u otra dependerá de los objetivos del curso y del cumplimiento de las expectativas de los profesores y de los estudiantes (Dawson, 2017).

Tanto en un tipo de evaluación como en otro es importante dar a conocer por adelantado a los estudiantes los criterios de valoración. Newman (2007) recomienda incluso confeccionar estos criterios a través de "un manifiesto previo de intenciones», construido por los propios estudiantes, tras la discusión en los talleres. A partir de este marco referencial la evaluación se desarrollará de modo homogéneo y estable por parte de los profesores, y orientará a los estudiantes hacia el autoaprendizaje, favoreciendo un desarrollo efectivo de las competencias buscadas. También Joseph et al. (2020) discuten la eficacia de la rúbrica para el progreso del aprendizaje de los estudiantes si antes no queda completamente claro el contenido de los requisitos exigidos; de ahí que recomienden la incorporación de los estudiantes al diseño de las rúbricas.

Una rúbrica consta de tres elementos: un criterio de evaluación, una definición de la calidad y un sistema de puntuación (Dawson, 2017: 3) y puede ser desarrollada a través de modalidades de trabajo o de comportamiento (trabajo escrito, presentaciones, debates, etc.). Para que resulte eficaz deberá siempre resultar fiable y válida. 
La fiabilidad de la rúbrica supone la reducción al mínimo del margen aleatorio de error (Ashton y Davies, 2015). Esta condición solo puede ser comprobada al final del proceso de aprendizaje y evaluación, cuando un procedimiento de medición arroja los mismos resultados en ensayos repetidos (Carmines y Zeller, 2005: 11); por tanto, para que la rúbrica se mantenga fiable, debe estar siempre abierta a su posible afinación. En cuanto a la validez, la rúbrica es válida si consigue medir eficazmente el aprendizaje pretendido como objetivo docente (Moskal y Leydens, 2000; Miller, Linn, y Gronlund, 2013). Validez y fiabilidad no son cualidades fáciles de conseguir, pues la rúbrica puede resultar en ocasiones demasiado general, o mecánica o centrada en aspectos formales, importantes pero insuficientes para abordar todos los asuntos de interés de un trabajo (Weigle, 2002). Por eso, una buena rúbrica de «escritura creativa» abarca todos los aspectos y niveles del texto, tanto los referentes a las propiedades del lenguaje como a su creatividad (entendido «lo creativo» en el sentido de original, divergente y personal), tomando en cuenta la utilización y revisión de las tradiciones literarias y atendiendo a la expresión personal y a los temas tratados. A través de la rúbrica será posible atender a cuestiones concretas del texto -narrador, voz, imagen, escenario, caracterización, mundo, historia, estructura, estado de ánimo y atmósfera, tono, diálogo o trama- superando así la valoración impresionista (Rodríguez, 2008; Mozaffari, 2013; Morris y Sharplin, 2013; Tung, 2015; Dawson, 2017). Pero, como es obvio, no es fácil llegar al consenso sobre los parámetros de revisión (Baer y McKool, 2009; Blomer, 2011; Mozaffari, 2013); por ello conviene variar con frecuencia las rúbricas para evitar que solo enfaticen aspectos del contenido, o de la forma lingüística, o no sirvan para detectar el progreso real, etc.

Por otra parte, una cuestión principal que preocupa a los profesores de los títulos de escritura creativa es la de decidir si la valoración de un curso académico debe hacerse en función de los resultados finales o más bien a través de todo el proceso de la escritura.

En este sentido Jame Wilson, profesor asistente de inglés en Diablo Valley College (Community College, en Pleasant Hill, California) (Davenport, 2017), considera que hasta un $50 \%$ de la calificación del estudiante podría ser otorgada no solo a la participación en las clases sino también al aprovechamiento de los comentarios a la propia escritura (incluso cuando se desechan las sugerencias). Es decir, la escritura es un proceso y conviene tener claro qué pasos lo conforman: el boceto, el borrador para taller, la revisión con los comentarios y el producto final. Por eso los docentes de un curso de escritura deberían valorar muy especialmente la perseverancia y persistencia de los estudiantes en mejorar sus borradores. Aunque en un programa de escritura se solicitan resultados y, de hecho, contar con plazos de entrega de los textos ayuda al estudiante a culminarlos, la atención a los borradores pone el énfasis en el proceso de la escritura y no tanto en el resultado. De ahí que la mayoría de los programas de escritura soliciten a los estudiantes la entrega no solo de los resultados finales sino también de todos los borradores realizados, con un registro del proceso y retroalimentación seguido, ya que solo a través de los borradores es como el estudiante puede demostrar su progreso (Holland et al., 2003).

Un procedimiento sencillo para seguir los borradores de los estudiantes es el portafolio, a través del cual el estudiante puede compartir con sus compañeros su progreso y aprendizaje. El portafolio es un cuaderno de colaboraciones auto-reflexivas sobre el trabajo generado por un estudiante a lo largo del curso, en el cual se integran los borradores, las correcciones del profesor y las observaciones de sus compañeros (Arter y McTighe, 2000). El contenido del portafolio sirve al interesado y a toda la clase pues fomenta la cohesión del grupo, favorece la confianza entre profesores y alumnos, y enseña a los estudiantes la importancia del proceso en la escritura, que conlleva siempre estudio, investigación sobre las técnicas y autoevaluación.

La eficacia del portafolio dependerá, como es lógico, de la puntualidad de los comentarios del profesor acerca de los resultados de los estudiantes, de su detalle y justificación, y de la coherencia y consistencia con los criterios preestablecidos. Entre las rúbricas recomendables para el portafolio se encuentran las metas de aprendizaje, el desarrollo de la propia personalidad, la colaboración con el resto del curso y el aprovechamiento de los materiales y recursos disponibles (Nezakatgoo, 2011: 755). En cualquier caso, los comentarios directos e individuales del profesor al trabajo de los estudiantes se han demostrado el sistema de evaluación más formativo, según han constatado las investigaciones sobre el feedback de la enseñanza en una variedad de escuelas y disciplinas (Taylor y Burke da Silva, 2014; Graham, Herbert y Harris, 2015). Y más formativo aún es el comentario que invita a la investigación y al diálogo, en lugar de resolver los problemas (según matiza Perry, 2004). 
Estos comentarios directos llegan al estudiante de escritura creativa no solo a través del profesor sino también de parte de sus compañeros de curso (pares). La revisión por pares tiene la ventaja de minimizar el riesgo de que las rúbricas acaben imponiendo en los estudiantes un modo de trabajo ajustado a los estándares de valoración de los profesores (MacKinnon, 2001).

Para que la evaluación por pares sea eficaz es necesario instruir previamente a los estudiantes sobre las características generales del proceso de evaluación y acerca de la aplicación de las rúbricas (Newman, 2007). Además de recordar que la evaluación atañe solo a lo explicado o propuesto en el aula es conveniente ofrecer a los estudiantes evaluadores buenos ejemplos de retroalimentación antes de implementar el proceso. Entre las buenas prácticas aconsejadas estaría: 1) el hábito de comenzar cualquier evaluación con los comentarios positivos, para después abordar las sugerencias de mejora, y 2) el anonimato de la retroalimentación, para facilitar su libertad y eficacia, así como, 3) en la medida de lo posible, la cantidad de revisiones por pares que se ofrece por cada ejercicio.

Sin embargo, no todos los investigadores son partidarios del sistema de evaluación por pares e incluso se ha constatado cierto descontento de los estudiantes sobre este sistema (Ashton y Davies, 2015: 4). En efecto, una buena retroalimentación requiere de observaciones detalladas y frecuentes, convenientemente justificadas, orientadas pedagógicamente a los aspectos en que el estudiante puede mejorar realmente, teniendo en cuenta la formación adquirida, comentarios que no siempre un estudiante puede realizar por falta de madurez o capacitación.

Finalmente, la autoevaluación es el otro gran procedimiento formativo que logra, principalmente, involucrar al estudiante en la responsabilidad de su propio aprendizaje. Aprendiendo a revisar su texto el estudiante será capaz de anticiparse a los posibles juicios de los profesores y compañeros y logrará concentrar su esfuerzo en la consulta de puntos determinados que no puede resolver por sí mismo. En este sentido, Mozaffari (2013) ha experimentado la concordancia que puede llegar a alcanzarse entre la evaluación de los expertos y la autoevaluación.

\section{RÚBRICAS DE EVALUACIÓN}

La investigación actual ha demostrado que la valoración en función de criterios analíticos es la técnica más fiable para juzgar la creatividad (Mozaffari, 2013: 2215) y que el empleo de una rúbrica representa el procedimiento más adecuado en el campo de la escritura creativa (Morris y Sharplin, 2013). Como define Brookhart, la rúbrica es el conjunto coherente de criterios utilizados para evaluar el trabajo de los estudiantes e incluye ilustración sobre los niveles de rendimiento en esos criterios (Brookhart, 2013: 4).

Según defienden muchos autores el empleo de rúbricas puede resolver en parte el problema de la subjetividad en la evaluación de la escritura creativa (Griffin y Anh, 2005; Rodríguez, 2008; Mozaffari, 2013; Morris y Sharplin, 2013). La rúbrica es un sistema que facilita, tanto a docentes como a estudiantes, la concreción de los objetivos de aprendizaje y de producción creativa, y permite valorar el progreso en la escritura, así como el rendimiento en los resultados finales (Brookhart, 2013). Además de hacer más objetiva la corrección de los textos la hace más rápida (Vaezi y Rezaei, 2019) y, por tanto, más formativa, pues no debe olvidarse que la evaluación se orienta principalmente a favorecer un proceso de aprendizaje. A la objeción de que la rúbrica puede producir una homologación de estilos en los escritores oponen algunos autores que su efecto es justo el contrario, el estímulo de la creatividad, el desarrollo de habilidades para localizar un lenguaje propio, la incorporación de ideas nuevas y el esfuerzo por alcanzar una organización coherente del texto. Y, sobre todo, la comprensión de lo creativo como un proceso, no como un milagro espontáneo (Burke, 2003). Además, la rúbrica sirve no solo para valorar los textos sino también los proyectos de trabajo o las interacciones con los compañeros de escritura y los proyectos de trabajo. Sin embargo, precisa Kevin Price (2019), no ha de olvidarse que hay diferencias esenciales entre la escritura a la que se asigna función retórica, y la escritura que es consecuencia del acto de creatividad, lo que también implica una serie de cautelas a la hora del diseño de rúbricas. A la vez Lindesy Carruthers y Roy MacLean (2019) previenen de la naturaleza mudable y en continua transformación de lo que consideramos «creativo", hecho que naturalmente influye en la designación de los parámetros de evaluación.

El problema radica en la definición de cuáles deban ser los enunciados de valoración que atienden a los atributos verdaderamente relevantes de la escritura creativa (Blomer, 2011; Mozaffari, 2013). Las opiniones más generalizadas señalan cuatro rasgos definitorios: historia, voz, imagen y caracterización de los personajes (Mills, 2006; Burroway, 2011). Y al contrario, serían signos de una carencia creativa la falta de precisión, de comprensibilidad y de plasticidad (Morris y Sharplin, 2013) ${ }^{4}$. 
Existen multitud de rúbricas prediseñadas para la valoración de todos los géneros literarios, disponibles para los docentes en publicaciones académicas, en bancos digitales de provisión de rúbricas prediseñadas, o bien adscritas a programas académicos concretos. Las que cuentan con más ejemplos son las relativas a la narración y al ensayo, como corresponde a la primacía de este último género en las clases de composición, y al relato breve en los talleres de escritura. Sin embargo, lo más eficaz es el diseño específico de la rúbrica en función de los objetivos del programa, de la materia y del tipo de estudiantes. Por otra parte, ha de tenerse en cuenta que dependiendo de los géneros literarios practicados, el tipo de público al que se aspira o el tema incluso, variará el modo de redacción y de aplicación de la rúbrica.

En la selección de los criterios intervienen principalmente los expertos en el campo (profesores de escritura, escritores y editores), pero también se puede incorporar a la redacción de la rúbrica a los estudiantes. Janet Files (Davenport, 2017), especialista del departamento de educación de South Carolina y directora del programa nacional Coastal Area Writing Project, defiende que esta opción fomenta la iniciativa y motivación del estudiante y lo involucra en el proceso de aprender a leer como un escritor, que es de lo que un curso de escritura trata: hacer que el estudiante se haga consciente de que las técnicas seleccionadas por un autor guardan relación directa con su intención creativa y con el legado de la tradición literaria. En opinión de Davenport (2017), que también apoya este sistema, es más fácil lograr el aprendizaje de los estudiantes si todos los que participan en el curso conocen claramente los criterios de valoración que serán empleados para medir el rendimiento. Por esta razón propone compartir la evaluación de los textos entre la calificación asignada por compañeros (pares) e incluso por el propio autor.

Los criterios de la rúbrica vienen orientados por un marco de evaluación que, en el caso de la escritura creativa, no es otro que la teoría literaria y la técnica de la composición (Rodríguez, 2008). Pero también podría tenerse en cuenta como principio valorativo en la rúbrica el efecto que el texto produce en el receptor. La capacidad de conmover ("to move the audience»), como planteó Peters (1990), es el elemento crucial para valorar una obra creativa. Por eso muchos docentes consideran que en los textos de escritura creativa debería valorarse la capacidad de «conmover o afectar» al lector (Mozaffari, 2013), un elemento que por lo general se deja fuera de la rúbrica por su difícil valoración, ya que depende de muchas circuns- tancias contextuales. Valorar la escritura en función de su efecto es arriesgado, ya que podría empujar a los estudiantes a querer "gustar» a su público, comprometiendo así su libertad y autenticidad.

Pero ya que el "efecto» será, en parte, lo que decida en el futuro la aceptación de los lectores, tampoco parece completamente desaconsejable, opina Jason Renshaw (2010), de la Facultad de Educación en la Universidad de Melbourne. Es necesario enseñar a los estudiantes a enfrentarse con un público y a considerar que sus textos "causan un efecto». Renshaw sugiere que la calificación de la escritura creativa se haga con el promedio de lo otorgado al estudiante por el profesor (sobre aspectos técnicos y de argumentación) y por el público de estudiantes (en función del efecto de la lectura). Con esta prima de orientación Renshaw sugiere una rúbrica explicativa que comprende los siguientes puntos:

\section{a) Argumentación}

Máximo: utiliza una evidencia válida, precisa, apropiada y variada para apoyar argumentos.

Adecuado: la evidencia es apropiada y relevante.

Suficiente: evidencia limitada proporcionada.

Insuficiente: se proporciona poca o ninguna evidencia.

Con una escala de cinco niveles de graduación en una calificación descendente de 5 a 1 .

\section{b) Organización y cohesión}

5: el trabajo funciona bien en su conjunto. El texto sostiene un flujo claro y una unidad de propósito.

4: la respuesta es vigorosa y desarrolla bien el cuerpo de la argumentación, pero hay puntos menos interesantes.

3: desigual. Las transiciones son torpes o faltan. La cohesión del texto es débil.

2: insuficiente. Divaga. Es repetitivo y poco concluyente.

1: incorrecto. Es incoherente, fragmentario, e insuficiente para poder llegar a alguna conclusión.

\section{c) Voz}

5: el tono del discurso es seguro, apropiado para lo que se trata, consistente, comprometido y activo, natural. Se percibe la presencia tanto del autor como del público lector.

4: la voz se muestra en ocasiones excesivamente interesada, tiende a la manipulación o, al contrario, parece demasiado ajena al asunto, pasiva, apagada. 
3: el tono es apropiado pero impersonal, apático, artificial, demasiado formal o demasiado informal. El texto podría haber sido escrito por cualquiera.

2: aburre.

1: no se puede percibir el tono por los problemas de argumentación y de exposición.

\section{d) Creatividad- originalidad}

5: excelente uso de las imágenes con descripciones vívidas y detalladas, lenguaje figurativo, juegos de palabras, metáfora, ironía. Sorprende al lector con asociaciones inusuales, rompe convenciones, frustra expectativas.

4: algunas imágenes son sorprendentes, hay asociaciones inéditas, pero la conclusión es débil, y las imágenes y comparaciones menos originales. En algunos casos es inconsistente.

3: sentimental, predecible, o cliché.

2: toma prestadas ideas o imágenes de la cultura popular de manera irreflexiva.

1: la respuesta es superficial. Falta motivación o escasa comprensión de la tarea.

También combinando la evaluación de expertos (profesores) y de pares (compañeros de curso) el escritor y profesor de escritura creativa Kevin Allardice (2018) de la Mercy High School de Burlingame, California, sugiere otorgar la calificación de la escritura creativa según un porcentaje que abarque tanto el texto creativo (de ficción o no ficción) como el ensayo explicativo aportado por el autor, junto con la retroalimentación dispensada por los compañeros del curso. Para este fin Allardice solicita a los autores que redacten en tercera persona un ensayo reflexivo y explicativo sobre su propia obra, con un lenguaje neutral, declarando la intención pretendida en su texto. Por otra parte, se incluye en la evaluación no solo el texto final sino todos los materiales que rodean la parte creativa. El objetivo de Allardice es lograr medir el éxito del efecto buscado por el autor, y ver la conexión entre la reflexión crítico-creativa del autor y la satisfacción de las expectativas buscadas en la reacción de los lectores. Con este fin propone las siguientes preguntas para la evaluación: "¿Qué detalles, citando pasajes específicos, sirven para conseguir el objetivo o efecto? ¿Qué aspectos específicos podrían revisarse para ayudar al autor a alcanzar la meta establecida?»

Este es también el sistema seguido en el Máster en Escritura Creativa de la Universidad Complutense de
Madrid (última edición en 2019), tanto para la evaluación de algunas materias como para la composición del trabajo final de máster. En el trabajo final de máster los estudiantes presentan su obra precedida de un ensayo crítico sobre lo que juzgan sus logros, y en él demuestran el proceso de aprendizaje y de absorción de modelos, fuentes y consideraciones críticas en todas las asignaturas, en el diálogo con sus compañeros y tratando de ser conscientes de los retos pendientes en su escritura.

Según sugiere Rodríguez Romero (2018: 34) conviene no aplicar en la rúbrica más de seis ítems de valoración, aunque estos ítems puedan subdividirse (entre tres y seis niveles), ya que un número excesivo de criterios dispersaría el análisis haciéndolo ineficaz. Una prueba de esta afirmación deriva del experimento de Ashton y Davies (2015) con la rúbrica creada para la valoración de textos en un Massive Open Online Course (MOOC), confeccionada tras la consulta con siete expertos en la temática de ciencia ficción y fantasía y recursos MOOC, incluidos agentes literarios, editores y escritores. A estos expertos se les indicó que se buscaban juicios probatorios y no impresionistas, de modo que, en lugar de afirmar cosas como "la historia me atrae, se debería optar por declaraciones del tipo: «a lo largo de la historia puedo identificar un conflicto sólido que convence» y, en lugar de «la presentación me pareció extremadamente bien escrita y atractiva» sería preferible algo así como «la prosa cambia regularmente y sin problemas entre oraciones simples cortas y oraciones largas y complejas». A los expertos se les facilitaron puntos de análisis para favorecer la objetividad de los juicios. Los parámetros valorados en la rúbrica fueron cinco:

1.Visión de conjunto: en función del género utilizado y el público previsto. Se trata de juzgar si el texto es atractivo y está bien escrito.

2. Variedad: la prosa fluye con diversidad y sin problemas, alternando oraciones simples cortas y oraciones largas y complejas.

3. Interés: el comienzo de la escena atrapa alguna de estas razones: una pregunta sin respuesta, una visión, una escena dramática o deslumbrante, una desconexión lógica, cierta intriga, las palabras de algún personaje que prometen una acción interesante...

4. Situación: el lector se hace cargo en todo momento del lugar donde se encuentran los personajes y de la distancia que mantienen entre sí, así como de su relación con el espacio.

5. Ortografía: no hay errores ortográficos que distraigan de la lectura. 
En el estudio de Ashton y Davies se eligieron tres muestras de escritura que fueron ordenadas de modo unánime por los expertos, desde la calidad creativa inferior a la superior. La selección se estableció por consenso, no por número. El estudio demostró que las evaluaciones difieren cuando se solicita una valoración general y cuando se requiere la atención del evaluador hacia un solo aspecto, siendo más elevada la primera con relación a la segunda (Ashton y Davies, 2015: 17). También es evidente que los dominios más simples son más homogéneos en la valoración.

Así pues, conviene centrar bien la selección de criterios y decidir también si la redacción de los mismos se hará de forma sintética o acompañada de una guía que explique cómo habrá de entenderse cada criterio contemplado, es decir, una «rúbrica instruida». Este procedimiento se demuestra especialmente útil en la valoración entre pares. Una vez definidos los criterios, Mary J. Allen (2014), de Miami-Dade College, recomienda detallar los extremos opuestos de excelencia y deficiencia que se contemplan como resultados, los cuales servirán de punto de referencia para los pasos intermedios. Las categorías examinadas por Allen son: "no cumple las expectativas», "necesita mejorar», "cumple con las expectativas» o "excede las expectativas», valoraciones que se concretan en una variedad de ítems y grados de proporcionalidad.

En cuanto a los apartados que Allen sugiere para la evaluación específica del texto, menciona la organización y el análisis del contenido 5 .

En la visión de Burroway (2011) la rúbrica debería contener cuatro niveles diferentes de gradación (alto, medio, aceptable y bajo) aplicados a los siguientes ítems valorativos: imagen, voz, caracterización e historia. En cada uno de estos puntos, los autores incluyen instrucciones detalladas de lo que debe buscarse detallando el nivel "máximo» y "mínimo» de realización. El «mínimo» lo constituiría la «escritura plana» (centrada en lo abstracto, a través de conceptos no experimentables ni tangibles para el lector), plagada de generalizaciones (categorías que no se pueden visualizar y son meramente informativas) y juicios (indicaciones de cómo debe actuar el lector en relación con el texto o los personajes), mientras que el «máximo» es el de la "escritura creativa», que trata de conseguir que sea el propio lector quien deduzca la información, los juicios o abstracciones incluidas en el texto, a través de indicaciones e imágenes. En función de estas previsiones la «imagen literaria» podría ser definida como aquella palabra o serie de palabras que afectan a uno o más de nuestros sentidos
(Burroway, 2011: 15) y congregan en sí el máximo de la creatividad de un texto (Mills, 2006: 12). Otras indicaciones se realizan para la voz, el gran "activo» del escritor, donde se manifiesta su sensibilidad, y a través de la cual se generan imágenes originales; como también la caracterización (directa o indirecta, por medio de detalles y sugerencias) y la valoración de la historia (a través de la cual se aparta el autor de la escritura plana) etc. En función de estas y otras indicaciones, la rúbrica se desarrolla como una descripción del éxito en estos criterios. En el menor grado, por ejemplo, se detallaría:

Imagen: pobre, el trabajo está repleto de juicios y generalizaciones.

Voz: pobre, no hay imágenes atractivas en el texto.

Caracterización: pobre, el personaje se desarrolla a través de descripciones simples.

Historia: pobre, el propósito se transmite directamente en lugar de a través de la narrativa.

En el nivel superior, en cambio:

Imagen: excelente, el trabajo está libre de abstracciones, generalizaciones y juicios. En cambio, proporciona algunos detalles que implican los mismos conceptos.

Voz: excelente, el trabajo está repleto de imágenes para hacer atractiva la voz.

Caracterización: excelente, la personalidad del personaje se revela a través de sus acciones, en lugar de directamente.

Historia: excelente, la narración ofrece de modo indirecto la información y la intencionalidad de los personajes.

Por su parte, Somasundaran et al. (2018) han planteado un proyecto de automatización de rúbricas para valorar las cualidades de una buena narración dirigida a los niños. Más allá del objetivo de una evaluación computacional, una vez suministrados los criterios al sistema de la inteligencia artificial, lo interesante de esta propuesta es considerar las rúbricas que se han introducido en los procesadores inteligentes para la evaluación. A juicio de estos autores la narración debe tener en cuenta en sus descriptores tres parámetros: organización y objetivo del texto, desarrollo y cumplimiento de las reglas de corrección lingüística y estilo.

La cuestión de la organización revisa el texto desde una perspectiva global, valorando la coherencia de los acontecimientos, el inicio y el desenlace, y juzga si la 
trama enhebra todos los elementos de la historia. La escala de puntuación aplicada, es de 1 a 4, siendo 4 la puntuación más alta. Esta puntuación se otorga en el caso de que se cumpla la rúbrica:

a) Se mantiene a lo largo de todo el texto la organización, gracias a una trama efectiva.

b) El planteamiento del carácter ha sido bien dibujado y el escenario es claro.

c) Se utilizan constantemente variedad de estrategias para la transición de los acontecimientos.

d) La secuenciación de los eventos es natural y lógica.

e) El relato se abre y se cierra correctamente.

En relación al desarrollo de la historia se toma en cuenta el desenvolvimiento de la trama, si se plantean descripciones vívidas y si los personajes se han desarrollado suficientemente:

a) La narración utiliza detalles relevantes, diálogo y descripción.

b) Se desarrolla claramente al personaje y se sitúa en un escenario bien dibujado.

c) Hay conexión con todo lo planteado en el origen de la historia; se utiliza una variedad de técnicas narrativas.

d) Se usa un lenguaje plástico, concreto, sensorial.

e) El estilo es efectivo y apropiado.

En el apartado de las convenciones de lenguaje y estilo se analiza la competencia en el uso del lenguaje, examinando si el texto muestra un adecuado dominio de las convenciones lingüísticas: gramática, sintaxis, ortografía y puntuación.

Basándose en una versión modificada de la técnica Delphi, Vaezi y Rezaei (2019) han desarrollado una rúbrica de escritura narrativa pensada para uso de los docentes de escritura creativa y orientación de los estudiantes sobre la calidad esperada en sus trabajos finales. Este sistema sirve también como marco de orientación para la autoevaluación y la evaluación por pares. Esta rúbrica ha sido diseñada tras una exhaustiva revisión bibliográfica, a través de los resultados de un cuestionario distribuido entre dieciocho expertos (profesores, críticos, editores, escritores), validado en sucesivas rondas de examen, completado con entrevistas formales e informales y verificado en diecinueve muestras de escritura. Los ítems derivados de este trabajo fueron: voz narrativa, caracterización, historia, ambiente y atmósfera, lenguaje y mecánica de la es- critura, diálogo, trama, e imagen, definidos en cuatro niveles de rendimiento:

Máximo: siempre.

Destacable: la mayoría de las veces

Aceptable: algunas veces.

Insuficiente aunque apropiado: pocas veces

Inaceptable: pobre, inapropiado o inexistente.

El desarrollo de estos ítems sería el que podemos ver en la tabla 1.

En cuanto al sumatorio de la rúbrica, Newman (2007) sugiere que para una calificación de sobresaliente (70\% a $100 \%)$ el trabajo debería alcanzar el efecto y el agrado del lector en un alto nivel: se tratará de un trabajo logrado por la coherencia de tono, el control de las estrategias narrativas, una voz diferente y original, un uso creativo e ingenioso del lenguaje, la original capacidad de observación, el conocimiento de la variedad de estructuras narrativas posibles y de las tradiciones literarias que será capaz de seleccionar o subvertir. En el texto se trabajará de forma perfecta el diálogo, los diversos registros del lenguaje, la ortografía y la puntuación, la sintaxis y la presentación. La edición será impecable, dentro de los estándares de lo que un agente pediría para presentar a la publicación.

Para una calificación de nivel medio (60\% al 69\%), el trabajo será ambicioso, con un tono y voz narrativa diferenciados, aunque no en el mismo nivel de coherencia y originalidad de un trabajo excelente. El texto manifestará la comprensión de las estructuras y géneros elegidos, de la tradición y el contexto literario; manejará bien el diálogo, las expresiones hechas, describirá con detalles efectivos y tocará el tema de modo original. El manuscrito deberá cumplir con los estándares requeridos para la publicación.

Para un nivel del $40 \%$ al $49 \%$, el texto cumplirá con el estándar en cuanto a invención y competencia, planteando un tema discernible y una voz narrativa coherente, pero habrá inconsistencias en la caracterización de los personajes y en el desarrollo del argumento, la invención no será tan natural y original como en los otros niveles y, aun situándose dentro de lo correcto, tenderá al cliché.

Un trabajo que obtenga una calificación inferior al $40 \%$ no se considerará apto para un nivel de posgrado. Reflejará torpeza, pobreza de concepción, vacilaciones, incapacidad para seguir el desarrollo de un argumento, o bien resultará tedioso, falto de observación y detalle en las descripciones, de un tono co- 
Tabla 1.

- El vocabulario es rico y el estilo es flexible, apropiado a las situaciones, sucesos, acciones y emociones de los personajes y al significado que el escritor quiere transmitir en su historia.

Voz narrativa

- Se aportan detalles específicos que contribuyen a crear un ambiente de autenticidad, consistencia, credibilidad y completitud del mundo creado.

- El punto de vista es claro, consistente, coherente, apropiado al género que se utiliza.

- Las desviaciones de este criterio se producen por razones artísticas.

- El carácter de los personajes se revela indirectamente a través de su aspecto físico, acción, pensamientos, diálogos, lugares de emplazamiento o símbolos.

Caracterización historia.

- Los cambios o evolución de los personajes tienen lugar a consecuencia de los sucesos de la historia y su carácter siempre resulta verosímil y realista, porque se les concede tiempo suficiente para esta evolución y se explica esta evolución.

Ambientes y

- Las acciones, pensamientos y diálogos de los personajes, los sucesos y los emplazamientos de la historia se presentan siempre en un lenguaje apropiado y con un vocabulario que contribuye a establecer la impresión y la atmósfera que el autor quiere conseguir.

Atmósfera

- Se cumplen perfectamente las reglas de puntuación y gramática.

- Los diálogos sirven para la caracterización, introducen tensión, crean escenas, presentan acciones y sucesos, y no resultan un mero decorado.

Estilo y lenguaje

- El estilo, el lenguaje y los diálogos son congruentes con el personaje, su estatus social y su carácter.

- Antes del conflicto se ha realizado la presentación de personajes, ambientes, y se ha anticipado la trama.

- Se manejan correctamente las técnicas temporales, escena, relato sumario, diálogo, anticipación, retrospección.

Historia

- El cambio y la confrontación se desenvuelven a través de la conexión de causas y consecuencias.

- El cambio y la confrontación se desenvuelven principalmente a través de escenas, diálogos y relatos sumarios.

- El propósito de la historia se transmite implícitamente sin el uso de declaraciones formales.

- Los detalles concretos y significativos tienen resonancias sensoriales y sugieren nuevos

Imagen $\quad$ horizontes más allá de la interpretación literal de la historia. Se emplean con acierto y brillantez imágenes en el desarrollo de la historia.

\begin{tabular}{|c|c|}
\hline Decorado & $\begin{array}{l}\text { - El emplazamiento proporciona información y a la vez logra la emoción, dibuja un estado de } \\
\text { ánimo, ofrece señales de cambio, y es consistente y coherente con el propósito de la historia. } \\
\text { - El emplazamiento y decorado tienen efecto en las acciones y sucesos de la historia, en las } \\
\text { conductas de los personajes y en el dibujo general de la historia. El decorado produce la } \\
\text { impresión de variedad y logra implicar al lector en el máximo nivel, gracias a los efectos de } \\
\text { perspectiva logrados sobre la distancia, larga, mediana o corta. }\end{array}$ \\
\hline Argumento & $\begin{array}{l}\text { - Hay unidad artística en el argumento. Acciones, sucesos y escenas tienen lugar a consecuencia } \\
\text { de un orden lógico y no hay sucesos irrelevantes que obstaculicen el avance de la historia. } \\
\text { - Las acciones, sucesos y escenas se vinculan de modo causal y sirven para la significación de la } \\
\text { historia. } \\
\text { - Cada giro del argumento es justificado por los personajes o por las situaciones ya implicadas. }\end{array}$ \\
\hline
\end{tabular}

Fuente: elaboración propia sobre la base de Vaezi y Rezaei (2019). 
herente, y no será posible advertir con claridad en el texto lo que pretende el autor. Por otra parte, el trabajo demostrará el desconocimiento de la tradición en la que se encuadra, la redacción contendrá errores repetidos en todos los niveles y la presentación será descuidada.

Podrían añadirse aquí otras reflexiones sobre las rúbricas previstas por diferentes másteres universitarios de escritura creativa para valorar los resultados finales de sus estudiantes. Pero no podemos ocuparnos de este análisis en el espacio de este trabajo, en el que hemos analizado algunas de las fórmulas más empleadas para medir la competencia creativa en la evaluación continua de la práctica de la escritura en títulos universitarios. Mencionaremos solo las recomendaciones de los dos másteres universitarios oficiales de escritura creativa que se imparten en España, en la Universidad de Sevilla y en la Universidad Complutense de Madrid. En ambos el trabajo de fin de máster es un texto creativo (en cualquier género, modalidad y extensión) que se presenta acompañado de un ensayo reflexivo donde el autor o la autora explica el proceso de su escritura, los motivos de inspiración, autores de referencia, recursos de documentación, marco genérico conocido o recursos aprendidos en el máster. La evaluación del trabajo de fin de máster tiene en cuenta la aplicación al trabajo creativo de todas las destrezas desarrolladas a lo largo del curso y demanda que se detalle en el ensayo reflexivo la intención y efectos buscados con el texto, las dificultades con las que se ha encontrado o las decisiones tomadas sobre el planning de trabajo. En definitiva, el ensayo reflexivo que acompaña al texto creativo muestra el diario del proceso creativo atravesado a lo largo del curso y pone de manifiesto la asimilación de las materias impartidas y las prácticas desarrolladas. Desde este presupuesto el estudiante es capaz de analizar los modelos literarios, seleccionar las herramientas y estilos más adecuados, depurar su propio discurso o establecer una argumentación.

El texto deberá contar con la calidad literaria necesaria para ser publicado: será un texto correcto lingüísticamente, que manifieste una voluntad de estilo y una intencionalidad justificada a través de los recursos empleados. El trabajo de fin de máster se defiende en sesión pública ante un tribunal, a través de una exposición coherente y argumentada del proceso creativo y de los resultados aportados. Se trata pues de un ejercicio triple (contenido y argumentación, creatividad textual escrita y disertación oral) que sigue la técnica de la evaluación consensuada.
El tribunal calificador de los trabajos de fin de máster juzga separadamente el ensayo y la parte creativa, y otorga la calificación que resulta de la media aritmética de las valoraciones individuales. En el ensayo se valora el contenido, la organización y la corrección lingüística. En el texto creativo se tiene en cuenta la dificultad del tema o temas tratados, la relación entre la teoría y práctica, la originalidad de la propuesta, la integración, la actualidad, la riqueza estilística, etc. Las rúbricas se aplicarán según los diferentes géneros y tipos de discurso: argumentativo, expresivo, etc.

\section{CONCLUSIÓN}

En comparación con la ingente bibliografía relacionada con la enseñanza de la escritura creativa no son muchos los estudios recientes disponibles sobre su evaluación en sí, al margen de su relación con aplicaciones secundarias, ya sea el aprendizaje de una segunda lengua, el desarrollo del pensamiento crítico para la resolución de problemas o el hábito de la lectura crítica. En referencia a los estudios de escritura creativa en España y en Europa (salvo el Reino Unido) este vacío es muy acusado, como es lógico por la reciente implantación de este tipo de estudios de larga tradición anglosajona. Por eso, el objetivo de este trabajo ha sido enhebrar una argumentación convincente con las propuestas y recursos más útiles empleados en la valoración de la escritura creativa con finalidad estética.

La cuestión específica que nos ha interesado no ha sido tanto la valoración crítica de la escritura creativa (que puede ejercerse en entornos profesionales a través del mercado editorial) sino el problema de encontrar estándares que faciliten la evaluación de los productos realizados por los estudiantes que cursan títulos oficiales, a los se han asignado objetivos y competencias docentes. Considerando la novedad y carácter emergente de estos títulos universitarios en el territorio español, y su incipiente andadura fuera del entorno anglosajón, parece adecuado brindar un muestrario de estándares que pueda servir de orientación a los nuevos docentes, congregando de modo panorámico los hallazgos individuales de tantos profesores.

Por ello, en este trabajo hemos abordado la reflexión sobre los principales problemas que afronta la evaluación de los productos artísticos, y concretamente de la escritura creativa: su conveniencia y posibilidad, sus herramientas de medición y los sujetos que las emplean, los objetivos con los que se produce dicha evaluación en relación con la consecución de unas expectativas de progreso en la materia. Se ha trabajado 
con la bibliografía específica relativa a la evaluación (assessment) de la escritura en contextos de enseñanza del inglés como lengua primaria o como segunda lengua, primando los estudios que ofrecen resultados de aplicación de rúbricas para la creación literaria, si bien es cierto que lo principal en estos trabajos no es el resultado estético sino la medición de la personalidad creativa. Tras este análisis comprobamos que la discusión por parte de algunos sobre la imposibilidad de valorar la escritura creativa deriva de una concepción romántica y expresivista del hecho literario, que identifica la creación con resultados espontáneos o automáticos. Esta suele ser la postura general de la psicología de la educación y de la pedagogía, interesadas por el desarrollo de la «creatividad» mediante la «escritura creativa»; en cambio, los profesores de composición, más próximos a la idea retórica de la escritura, aceptan la idea de "escritura como proceso» y la posibilidad real del progreso creativo de los estudiantes como el movimiento exactamente inverso. El análisis de esta cuestión requeriría una discusión exclusiva que sobrepasa con mucho la extensión y finalidad de este artículo. Pero en todo caso, parece claro que la aplicación de estándares estéticos de valoración de la escritura creativa en sí misma (no ya por sus aplicaciones terapéuticas, analíticas, de desarrollo personal y crítico) puede redundar en muchos beneficios para el progreso de los estudiantes. Como sucede con la manipulación de cualquier instrumento, y la escritura es por antonomasia una «herramienta intelectual», llegar a la destreza, a través de un camino de superación de hitos de virtuosismo, no solo favorece la comprensión de la escritura como proceso ascendente y significativo, sino que construye también una plataforma para el descubrimiento y consecución de logros más altos. Es un sistema para valorar tanto los resultados obtenidos como el esfuerzo personal del estudiante, que se ve impulsado continuamente en su afán de superación.

\section{NOTAS}

1. Luqman Rababah (2018) en su adaptación del método Torrance al entorno de la escritura creativa define "lo creativo» por su fluidez, capacidad y profusión en la generación de nuevas ideas (en los distintos párrafos), grado de desarrollo (completo o no) y relación y pertinencia con lo que se propone como tema. La "flexibilidad» sería la capacidad de variar las ideas propuestas, evaluable según el grado de transformación, y la "originalidad», la capacidad de producir ideas o soluciones inusuales, únicas o altamente personales.

2. Variedad de esta técnica es el método de la puntuación instantánea pro-

\section{REFERENCIAS}

Allardice, Kevin (2018). The Oaks. Mercy High School. Burlingame. Spring 2018. Disponible en: https://issuu.com/mercyhsb/docs/the_oaks_-_spring_2018 [Fecha de consulta: 23 noviembre 2019].

Allen, Mary J. (2014). Using Rubrics to Grade, Assess, and Improve Student Learning. Miami-Dade College March 7, 2014. Disponible en: https://www.academia. edu/39389988/Using_Rubrics_to_Grade_ Assess_and_Improve_Student_Learning [Fecha de consulta: 24 octubre 2019].

Arter, Judy y McTighe, Jay (2000). Scoring rubrics in the classroom: Using perfor- puesto por Silvia, Marin y Nusbaum (2009) con el objeto de ofrecer una evaluación en los parámetros de la originalidad, el ingenio o la extrañeza (originality, cleverness, remoteness). En el método de Silvia los evaluadores examinan el conjunto completo de las respuestas y otorgan una calificación única en función de la singularidad y fluidez (unicidad de las respuestas que son más creativas) y abundancia de las ideas.

3. Baer y McKool (2009: 5) la recomiendan, concretamente, como procedimiento de la evaluación en educación superior.

mance criteria for assessing and improving student performance. Oaks CA: Corwin Press.

Ashton, Scott y Davies, Randall S. (2015). Using scaffolded rubrics to improve peer assessment in a MOOC writing course. Distance Education, 36 (3): 312334. https://doi.org/10.1080/0158791 9.2015.1081733

Baer, John y McKool, Sharon S. (2009). Assessing creativity using the consensual assessment technique. En: Christopher S. Schreiner (ed.). Handbook of research on assessment technologies, methods,
4. Para el diseño válido y fiable de las rúbricas pueden consultarse las instrucciones dadas por Dornisch y Sabatini McLoughlin (2006), Rochford y Borchert (2011), Timmerman et al. (2011), Huerta et al. (2014) y Dawson (2017).

5. Tales como: completo o incompleto, preciso o impreciso, lógico o ilógico, detallado, minucioso, creativo, original, sutil, sofisticado, sintético, analítico, integrador, con errores conceptuales mayores o menores, con flexibilidad o rigidez de valoración, con simplicidad o complejidad de pensamiento, perspicaz o confuso, relevante o redundante y obvio, bien documentado o no, organizado o desordenado, etc.

and applications in higher education. Rider University: IGI Global, pp. 65-77. https://doi.org/10.4018/978-1-60566667-9.ch004

Blamires, Mike y Patterson, Andrew (2014). Can Creativity be Assessed? Towards an Evidence. Informed Framework for Assessing and Planning Progress in Creativity. Cambridge Journal of Educa tion, 44 (2): 147-162. https://doi.org/10.1080/03 05764X.2013.860081

Blomer, Yvonne Elizabeth (2011). Assessment in creative writing. Wascana Review, 43 (1): 61-73. 
Brookhart, Susan M. (2013). How to Create and use Rubrics for Formative Assessment and Grading. Alexandria: ASCD.

Burke, Robert A. (2003). The Influence of Rubrics on High School Students' Creative Writing Skills. [Tesis de máster]. Defiance College: Ohio.

Burroway, Janet (2011). Imaginative Writing: Elements of Craft. New York: Penguin.

Carmines, Edward G. y Zeller, Richard A. (eds.) (2005). Reliability and validity assessment. Beverley Hills, CA: Sage.

Carruthers, Lindsey y MacLean, Roy (2019). The dynamic definition of creativity: Implications for creativity assessment. En Ronald A. Beghetto y Giovanni E. Corazza (eds.). Dynamic perspectives on creativity. New directions for theory, research, and practice in education. Springer, pp. 207-223. https://doi. org/10.1007/978-3-319-99163-4_12

Davenport, Aneesa (2017). Assessing Creative Writing Is Hard, So Here Are Three Ways to Avoid. Putting It into Words: The Future of Writing Instruction. Oct 2, 2017. Disponible en https://www. edsurge.com/news/2017-10-02-assessing-creative-writing-is-hard-so-hereare-three-ways-to-avoid-it [Fecha de consulta: 23 noviembre 2019]

Dawson, Philip (2017). Assessment Rubrics: Towards Clearer and More Replicable Design, Research and Practice. Assessment and Evaluation in Higher Education 42 (3): 347-360. https://doi.org/10. 1080/02602938.2015.1111294

Díaz Suárez, Saray (2015). Evaluating creative writing: the criterion behind short stories' assessment. [Tesis de máter] Universidad Autónoma de Barcelona: Barcelona. Disponible en https://ddd. uab.cat/record/137423

Dornisch, Michele M. y Sabatini McLoughlin, Andrea (2006). Limitations of webbased rubric resources: Addressing the challenges. Practical Assessment, Research, and Evaluation, 11 (3): 1-8.

Gotesky, Rubin y Breithaupt, Erwin. (1978) Creativity: A Metasociological Analysis. Philosophy and Phenomenological Research 39 (1): 23-41. https://doi. org/10.2307/2107028

Graham, Steve; Hebert, Michael y Harris, Karen R. (2015). Formative assessment and writing: A meta-analysis. The Elementary School Journal 115 (4): 523 547. https://doi.org/10.1086/681947
Griffin, Patrick y Anh, Phan Nguyet (2005). Assessment of creative writing in Vietnamese primary education. Asia Pacific Education Review 6 (1), pp. 72-86. https://doi.org/10.1007/BF03024969

Harper, Graeme (2016). Teaching Creative Writing. En Rodney H. Jones (ed.) The Routledge Handbook of Language and Creativity. New York: Routledge, pp. 498-512.

Holland, Siobman; Butt, Maggie; Harper, Graeme y Wandor, Michele (2003). Creative writing: A good practice guide. English Subject Centre. Report Series, 6. Disponible en http:// english.heacademy.ac.uk/wp-content/ uploads/2015/10/cwguide.pdf [Fecha de consulta: 23 noviembre 2019].

Huerta, Margarita; Lara-Aleci, Rafael; Tong, Fuhui e Irby, Beverly J. (2014). Developing and Validating a Science Notebook Rubric for Fifth-Grade Non-Mainstream Students. International Journal of Science Education 36 (11): 1849-1870. https://doi.org/10.1080/09500693.201 3.879623

Joseph, Sue A.; Rickett, Carolyn.; Northcote, Maria. y Christian, Beverly. J. (2020). 'Who are you to judge my writing?': Student collaboration in the coconstruction of assessment rubrics. New Writing, 17 (1): 31-49. https://doi. org/10.1080/14790726.2019.1566368

Kaufman, James C. y Baer, John (2012). Beyond new and appropriate. Who decides what is creative? Creativity Research Journal 24 (1): 83-91. https://doi. org/10.1080/10400419.2012.649237

Kaufman, James. C.; Baer, John. y Cole, Jason. C. (2009). Expertise, domains, and the Consensual Assessment Technique. Journal of Creative Behavior, 43 (4): 223-233. https:// doi.org/10.1002/j.2162-6057.2009. tb01316.x

Kozbelt, Aaron; Beghetto, Ronald. A. y Runco, Mark A. (2010). Theories of creativity. En James C. Kaufman y Robert J. Sternberg (eds.). The Cambridge Handbook of Creativity. Cambridge: Cambridge University Press, pp. 20-47. https://doi.org/10.1017/ CBO9780511763205.004

Kroll, Jeri (1997). A or C: Can we assess creative work fairly? Disponible en https:// dspace2.flinders.edu.au/xmlui/handle/2328/15073 [Fecha de consulta: 4 septiembre 2019].
Luft, Julie (1997). Design your own rubric. Science Scope, 20: 25-27.

MacKinnon, Maria Moira (2001) Using observational feedback to promote academic development, The International Journal for Academic Development, 6: 21-28. https://doi. org/10.1080/13601440110033689

Miller, Michael D.; Linn, Robert L. y Gronlund, Norman E. (2013). Measurement and assessment in teaching. New Jersey: Pearson.

Mills, Paul (2006). The Routledge Creative Writing Course Book. New York: Routledge.

Morris, Gerard y Sharplin, Elaine (2013). The Assessment of Creative Writing. English in Education 47 (1): 49-65. https://doi.org/10.1111/eie.12004

Moskal, Barbara. M. y Leydens, Jon A. (2000). Scoring rubric development: Validity and reliability. Practical Assessment, Research and Evaluation, 7 (10): 71-81.

Mozaffari, Hamideh (2013). An Analytical Rubric for Assessing Creativity in Creative Writing. Theory and Practice in Language Studies 3 (12): 2214-2219. https://doi.org/10.4304/ tpls.3.12.2214-2219

Newman, Jenny (2007). The Evaluation of Creative Writing at M.A. Level (UK). En Steven Earnshaw (ed.). The Handbook of Teaching Creative Writing. Edinburg: Edinburg University Press, pp. 24-36.

Nezakatgoo, Behzad (2011) Portfolio as a viable alternative in writing assessment. Journal of Language Teaching and Research, 2 (4): 747-756. https://doi. org/10.4304/jltr.2.4.747-756

Perry, Tonya (2004). The Art of Grading Papers Quickly and Effectively. English Journal, 94 (1): 115-119. https://doi. org/10.2307/4128859

Peters, Cheryl (1990). Applause, applause: Evaluating creative response and projects. Annual meeting of the National Council of Teachers of English, Atlanta, GA, November 16-21, 1990.

Price, Kevin (2019) The writing teacher: rethinking assessment and transformative learning in the creative writing classroom. New Writing. The International Journal for the Practice and Theory of Creative Writing, 17 (4): 463-470. https://doi.org/10.1080/14790726.201 9.1699577 
Rababah, Luqman. (2018). An adapted version of Torrance test of creative thinking (TTCT) in EFL/ESL writing: a rubric scoring and a review of studies. International Journal of English and Education, 7 (2): 128-136.

Rensahw, Jason (2010). How do we grade creative writing? Learning Twigs. Disponible en https://jasonrenshaw.typepad.com/ jason_renshaws_web_log/2010/04/howdo-we-grade-creative-writing.html [Fecha de consulta 24 octubre 2019].

Rezaei, Ali Reza y Lovorn, Michael (2010). Reliability and validity of rubrics for assessment through writing. Assessing writing, 15 (1): 18-39. https://doi. org/10.1016/j.asw.2010.01.003

Rochford, Linda y Borchert, Patricia S. (2011). Assessing Higher Level Learning: Developing Rubrics for Case Analysis. Journal of Education for Business, 86 (5): 258-265. https://doi.org/10.1080/ 08832323.2010 .512319

Rodríguez, Alicia (2008). The 'Problem' of Creative Writing: Using Grading Rubrics Based on Narrative Theory as Solution. New Writing. The International Journal for the Practice and Theory of Creative
Writing, 5 (3): 167-177. https://doi. org/10.1080/14790720802209963

Rodríguez Romero, Olga Neida (2018). As sessing through rubrics; an effective tool to improve writing in upper secondary students [Tesis de máster]. Universidad de Piura: Piura (Perú). Disponible en https://pirhua.udep.edu.pe/handle/11042/3757

Silvia, Paul J.; Martin, Christopher y Nusbaum, Emily C. (2009). A snapshot of creativity: Evaluating a quick and simple method for assessing divergent thinking. Thinking Skills and Creativity, 4 (2): 79-85. https://doi.org/10.1016/j. tsc.2009.06.005

Somasundaran, Swapna; Flor, Michael; Chodorow, Martin; Molloy, Hillary; Gyawalli, Binod y McCulla, Laura (2018). Towards Evaluating Narrative Quality. Student Writing. Transactions of the Association for Computational Linguistics, 6: 91-106. https://doi.org/10.1162/ tacl_a_00007

Taylor, Craig y Burke da Silva, Karen (2014). An analysis of the effectiveness of feedback to students on assessed work. Higher Education Research and Devel- opment, 33 (4): 794-806. https://doi.or $\mathrm{g} / 10.1080 / 07294360.2013 .863840$

Timmerman, Briana Crotwell; Strickland, Denise; Johnson, Robert L. Y Payne, John R. (2011). Development of a 'universal' rubric for assessing undergraduates' scientific reasoning skills using scientific writing. Assessment y Evaluation in Higher Education, 36 (5): 509-547. https://doi. org/10.1080/02602930903540991

Tung, Chan Kwong (2015). Assessment of Creative Writing: The Case of Singapore Secondary Chinese Language Curriculum. Universal Journal of Educational Research, 3 (10): 655-662. https://doi. org/10.13189/ujer.2015.031001

Vaezi, Maryam y Rezaei, Saeed (2019). Development of a rubric for evaluating creative writing: a multi-phase research. New Writing. The International Journal for the Practice and Theory of Creative Writing, 16 (3): 303-317. https://doi.org /10.1080/14790726.2018.1520894

Weigle, Sara Cushing (2002). Assessing writing. Cambridge: Cambridge University Press. https://doi.org/10.1017/ CB09780511732997 